\title{
PROPOSTA DIDÁTICA LÚDICA NA EDUCAÇÃO: EXPERIÊNCIAS COM CONTOS GIRATÓRIOS E COLABORATIVOS
}

\author{
LUDIC DIDACTIC PROPOSAL IN EDUCATION: EXPERIENCES WITH \\ COLLABORATIVE AND ROTARY TALES
}

\author{
Daniel Valério Martins* \\ Ruan Rocha Mesquita**
}

\begin{abstract}
RESUMO: Este artigo foi desenvolvido com base em experiências nas turmas de pedagogia da Universidade Federal da Paraíba - UFPB. Mostra-se uma proposta de atividades realizadas em duas turmas de pedagogia no semestre 2019.2 com dinâmicas de grupo lúdicas e análogas, com a utilização de contos infantis na busca por novas metodologias de ensino frente aos problemas enfrentados por docentes no dia a dia. Tem-se como objetivo incentivar uma maior aproximação entre professores e alunos no processo de ensino-aprendizagem, além de desenvolver mecanismos de mediação. Como suporte teórico, foram trabalhados os pensamentos de GINZBURG (1990); VIGOTSKI (2001); MONTESSORI (1965); HOFFMANN (2005); KISHIMOTO (2008); FREIRE (2002); FREINET (1975) e LOZANOV (1984), em uma proposta com novas metodologias e ferramentas didáticas. Assim, o presente artigo possui uma perspectiva puramente qualitativa e apresenta desenhos didáticos e metodologias para atenuar problemas de interação em sala de aula com a utilização de contos e o desenvolvimento de um processo de ensino com um olhar mais humano que resultou em de dois livros baseados na obra O Pequeno Príncipe.
\end{abstract}

ABSTRACT: This article was developed based on experiences in the pedagogy classes at the Federal University of Paraíba - UFPB. It is shown a proposal of activities performed in two pedagogy classes in the 2019.2 semester with ludic and analogous group dynamics, using children's stories in the search for new teaching methodologies for the problems faced by teachers daily. The objective is to encourage a closer relationship between teachers and students in the teaching-learning process, in addition to developing mediation mechanisms. As a theoretical support the thoughts of GINZBURG(1990); VIGOTSKI (2001); MONTESSORI (1965); HOFFMANN (2005); KISHIMOTO (2008); FREIRE (2002); FREINET (1975) and LOZANOV (1984) were worked, in a proposal with new methodologies and teaching tools. Thus, this article has a purely qualitative perspective and presents didactic designs and methodologies to alleviate problems of interaction in the classroom with the use of tales and the development of a teaching process with a more humane look that resulted in two books based on the work The Little Prince.

PALAVRAS-CHAVE: Metodologias, Contos, Didática.

KEYWORDS: Methodologies, Tales, Didactics.

\section{INTRODUÇÃO}

O presente artigo parte de uma triangulação de 3 conceitos básicos ao se trabalhar na educação em busca de uma efetivação no processo ensino-aprendizagem. Os conceitos em questão são: COMUNICAÇÃO; EMPATIA e LUDICIDADE. Estabelece-se uma conexão na justificativa de que, por meio de uma ação de transmitir uma mensagem e, eventualmente, receber outra mensagem como resposta, tenha-se a capacidade de projetar INTERLETRAS, ISSN N $N^{\circ}$ 1807-1597. V. 9, Edição número 34. Outubro, 2021/ Março de 2022- p

Dossiê: Educação, infância, diversidade e ensino de língua em contexto complexo. 
a personalidade de quem responde, de forma que o transmissor se ponha no lugar do outro de maneira empática, buscando fazê-lo por meio de jogos, brincadeiras, atividades criativas lúdicas, tornando o processo além de efetivo, mais prazeroso.

A ideia central desse artigo surge após ser desenvolvida uma atividade proposta às turmas de pedagogia, uma na disciplina de Avaliação da aprendizagem e outra na disciplina de Seminário Temático, ambas no semestre de 2019.2 nos turnos da manhã e noite respectivamente, do Centro de Educação, no Departamento de Metodologia da Educação, da Universidade Federal da Paraíba - UFPB, que resultou na publicação de dois livros, um deles, um E-book publicado pela Editora da UFPB e o outro publicado pela editora da Amazon.

Os livros foram resultados da realização de duas dinâmicas de grupo, a primeira chamada de "O Pequeno Príncipe" baseada na obra de Antoine de Saint-Exupéry de 1943, onde foram distribuídas frases e interpretações delas entre os alunos, encontrando os pares (entre as frases e interpretações contidas em pequenas cápsulas) e distribuindo abraços. Na segunda, dentro de uma das cápsulas distribuídas estava um papel escrito "prêmio", que consiste em um caderno com a frase "um caderno para as ideias de um jovem que quer mudar o mundo", nos remetendo à vida e obra do autor de $\mathrm{O}$ Pequeno Príncipe, quando ele não acreditava nas suas ideias e desenhos, sem a mínima noção do alcance e repercussão deles.

Assim surge a ideia do conto giratório e colaborativo onde as ideias de mudança de mundo seriam compartilhadas entre os futuros profissionais da educação, na busca de didáticas que gerem um sentido de cooperação e colaboração no papel de transformador de realidades e do mundo e assim remetendo a ideia de Freire (1979, p.84), quando nos diz que "a educação não transforma o mundo, transforma as pessoas e as pessoas transformam o mundo". Nesse sentido, o aluno que recebeu o caderno iniciou o conto, depois foi passado de mão em mão para que cada um pudesse complementar a história. Dessa forma, surgiram algumas indagações entre todos: como posso mudar o mundo? Qual meu papel no processo de mudança e transformação do mundo? E assim entrelaçaram com as verdadeiras funções do educador e as transformações geradas por meio da educação.

\section{O TRABALHO COM CONTOS GIRATÓRIOS E COLABORATIVOS}

O trabalho com a utilização de contos na educação trata-se de um exercício para o desenvolvimento da comunicação empática em um processo de pensar e refletir sobre o papel social, educativo, humanizando os indivíduos que compõem as sociedades nas quais estão inseridos.

Sabe-se o quanto a leitura literária, assim como o incentivo a interpretação textual e a mediação docente no processo ensino-aprendizagem são necessários, mas que, infelizmente, têm sofrido negligências frente ao pensamento acumulador de conteúdos presentes nas práticas das escolas e universidades. Por tanto, a dinâmica e o lúdico instigam que se crie muitas outras situações para tentar suprir tais brechas, tanto na INTERLETRAS, ISSN No 1807-1597. V. 9, Edição número 34. Outubro, 2021/ Março de 2022- p

Dossiê: Educação, infância, diversidade e ensino de língua em contexto complexo. 
formação de professores, quanto na formação destinada à escola básica e na formação humana nesse atual contexto de pandemia.

Outro aspecto, extremamente importante, é o fato de que a atividade lúdica propicia a criatividade, implicação pessoal, o pensar por si, contrapondo-se a um modus operandi recorrente na formação ocasionada pelas agências formadoras, predominantemente convertidas na reprodução de textos e de ideias, e não a sua produção.

Ademais, o uso de dinâmicas e contos giratórios e colaborativos propicia a escrita, o pensar coletivo e a transformação pessoal em um espiral de ideias que levam aos estudantes a experimentar um contexto de interdependência, frente ao outro e seu crescimento.

Como estratégia, nas dinâmicas, realizou-se previamente uma exposição teórica sobre a Metodologia Quantum Learning (5 princípios e 8 chaves de excelência), de Georgi Lozanov (1984); mostrou-se como exemplo os Contos: Por 4 esquinitas de nada, de Jérôme Ruillier (2014) e o Pequeno Príncipe de Antoine de Saint-Exupéry (1943); o Paradigma Indiciário de Ginzburg (1990); métodos e técnicas de Montessori (1965), Kishimoto (2008), Vigotski (2001), Freinet (1975) e Freire (2002), assim como com a avaliação mediadora proposta por Jussara Hoffmann (2005). E assim, toda uma teoria implicada na prática docente por um método humanizador e empático.

Ressalta-se, ainda, a pertinência e urgência de que futuros professores, em sua formação, tenham oportunidade de vivenciar situações de ensino que, como esta, possam ser realizadas junto aos estudantes com os quais irão lidar, em uma espécie de fazer e construir coletivo. Desta forma, eles experimentam estratégias de ensino-aprendizagem humanizantes, humanizando-se. Tais situações favorecem a reflexão acerca da viabilidade, de tais experiências serem realizadas nas escolas onde poderão atuar, assim como sobre a necessidade de possíveis adaptações e/ou recriações, fatores proporcionados pela ludicidade.

Assim, este artigo pode ser descrito como uma proposta didática humanizante de formação, por seus aspectos, em todo o encadeamento das suas etapas, em toda sua busca por coerência entre os princípios/objetivos mais amplos de formação e os modos de conduzir uma ação formadora no resgate à essência humana que aos poucos se perdem com o passar do tempo.

Segundo Marc Augé,

[...] é pelo fato de todo indivíduo humano ter consciência da presença nele de uma dimensão genérica que o torna capaz de sentir-se próximo de qualquer outro indivíduo. Sem essa transcendência íntima, a identidade individual é mutilada e incapaz de construir-se numa relação com os outros: nesse sentido, todos os racistas e todos os sexistas são enfermos. (AUGÉ,2014, p. 138-139)

Nesse sentido, as turmas tiveram uma oportunidade de vivenciar uma ação docente que não estava presa a um currículo fechado, monolítico, sem sentido. A experiência permitiu vivenciar ações em que a docência, mesmo diante de todos os ataques externos, pode favorecer o crescimento da pessoa como ser humano que está sempre em construção e

INTERLETRAS, ISSN $N^{\circ}$ 1807-1597. V. 9, Edição número 34. Outubro, 2021/ Março de 2022- p

Dossiê: Educação, infância, diversidade e ensino de língua em contexto complexo. 
reconstrução em um processo de alteridade. (MARTINS, MARTINS e ISAÍAS, 2020, p.44)

E por fim, observar a visão de mundo e transformação que ocorre na sociedade atual tendo como palco as escolas e universidade, buscando os pontos de congruência entre as culturas no que tange os saberes locais e globais quanto a uma educação humanizadora. De acordo com Augé (2014, p. 151) "todos nós nos associamos às conquistas da ciência, já que pertencentes à espécie humana. $\mathrm{O}$ homem genérico faz-se presença em cada indivíduo. O totalmente outro é igualmente um "Eu". Fora dessa equação, adeus humanidade."

\section{REFERENCIAL TEÓRICO DIDÁTICO}

Para o desenvolvimento deste artigo, toma-se por base vários estudiosos da área da pedagogia e humanidades como pilar de construção de atividades práticas, jogos, dinâmicas e processos de avaliação, que dentre os quais pode-se mencionar:

O pensamento de Ginzburg (1990, p.177), que para o autor tanto a história quanto outras disciplinas de humanidades partilham da prática de "rastreamento de sinais, indícios, signos" que remetem a algum evento, mas sem captá-lo em sua integridade. Nesse caso, associado aos contos trabalhados nas dinâmicas durante as aulas, utiliza-se o Paradigma Indiciário de Carlo Ginzburg, no intuito de identificar sinais, indícios e causas de problemas educacionais nas escolas, implícitos nos contos em formas de conceitos.

O pensamento de Montessori (1965), quando diz que o jogo é a principal atividade por meio da qual a criança leva sua vida durante os primeiros anos de idade, e desenvolve sentidos e noções com o contato, afirmação mencionada também em Piaget, apud Kishimoto, (1996, p. 95), quando diz que "agindo sobre os objetos, as crianças desde pequenas, estruturam seu espaço e o seu tempo, desenvolvem a noção de causalidade, chegando à representação e, finalmente, à lógica".

Por meio do jogo, o aluno passa a observar e investigar todos os objetos à sua volta de forma espontânea. Os alunos vão relacionar sua bagagem cultural com outras novas, desenvolver processos de aprendizagem individuais, essenciais para seu crescimento pessoal e social, independentemente do meio ambiente em que se desenvolve.

Segundo Montessori (1965, p.193) "os olhos assim se habituam a ver e reconhecer as formas que a mão está para tocar". Frente a tal afirmação, as dinâmicas e jogos, são trabalhados utilizando cores e formas com os docentes (alunos de pedagogia) com o propósito de mostrar que o processo de ensino-aprendizagem e avaliador pode ser prazeroso envolvendo ao mesmo tempo os três canais de aprendizagem: auditivo, visual e cinestésico como prega também a metodologia Quantum Learning de Lozanov (1984). Nesse caso, mostra-se com o exemplo do conto Por cuatro esquinitas de nada de Jérôme Ruillier, que um simples conto, utilizado em um momento de descontração, pode servir como o início de um processo de discussão e possível avaliação de interpretação textual crítica.

INTERLETRAS, ISSN $N^{\circ}$ 1807-1597. V. 9, Edição número 34. Outubro, 2021/ Março de 2022- p

Dossiê: Educação, infância, diversidade e ensino de língua em contexto complexo. 
De acordo com Kishimoto (2008, p. 148): O brincar também contribui para aprendizagem da linguagem. A utilização combinatória da linguagem funciona como instrumento de pensamento e ação. Para ser capaz de falar sobre o mundo, a criança precisa saber brincar com o mundo com a mesma desenvoltura que caracteriza a ação lúdica. [..] O que faz a criança desenvolver seu poder combinatório não é a aprendizagem da língua ou da forma de raciocinar, mas, as oportunidades que têm de brincar com a linguagem e o pensamento.

Baseia-se também em Freinet (1975, p. 172), ao qual se atribui a gestação do chamado "materialismo escolar", partindo da filosofia krausista, e nos diz que a filosofia de Karl Krause nas implicações pedagógicas explica e explora um contato direto entre o aluno com a natureza e com qualquer objeto de conhecimento por meio da experimentação, propondo a "autogestão, cooperação e solidariedade entre o alunado". Segundo o autor "a experimentação, sempre que isso for possível, pode partir tanto da observação, comparação, controle, quanto prova, pelo material escolar, dos problemas que a mente se formula e das leis que ela supõe ou imagina". Exatamente observado nos contos trabalhados, abrindo assim, espaço para uma conexão com o construtivismo de Vigotski.

Segundo Vigotski (2001), o seu "fazer em colaboração", trata-se de uma fase do processo de aprendizagem em que o aluno consegue fazer sozinho ou com a colaboração de colegas mais adiantados, o que antes fazia com o auxílio do professor, isto é, dispensa a mediação do professor. De acordo com Vigotski (2001), por meio da colaboração, a criança passa "a um grau intelectualmente superior, a possibilidade de passar, com a ajuda da imitação, do que a criança é capaz de fazer para o que ela não é capaz" (VIGOTSKI, 2001, p. 327), podendo ser vislumbrada tal ação no conto O Pequeno Príncipe, no momento que pensa sobre estratégias inclusivas partindo da observação e experimentação do personagem. Observa-se nesse momento um importante critério de verificação da eficácia do processo de ensino-aprendizagem em uma futura avaliação, que nesse caso, não dispensa o pregado por Hoffmann.

De acordo com Hoffmann (2005, p. 100), sua avaliação numa perspectiva mediadora, nos diz que tem a finalidade de acompanhar e favorecer a progressão contínua do aluno, por meio das etapas de "mobilização, experiência educativa e expressão do conhecimento". Nesse ponto, pode-se observar uma relação direta com os autores anteriormente citados, e assim encontrar a conexão entre todos na teoria de Lozanov.

No pensamento de Lozanov (1984, p.114), encontra-se sua Teoria da Sugestão à Aprendizagem e o Estudo Científico da Sugestão, denominada pelo autor de Sugestopedia, utilizando técnicas de relaxamento fazendo uso de músicas. Conectando todo esse conhecimento teórico contemplado e vislumbrado quando posta em prática na metodologia Quantum Learning, bombardeando de uma só vez os três canais de aprendizagem.

E por fim conectam-se com as ideias de Freire e Guimarães (2014), quando afirmam que "não é possível criar a disciplina intelectual castrando a imaginação, castrando a espontaneidade, castrando a expressividade da criança — de si mesma e do mundo que a cerca..." (FREIRE; GUIMARÃES, 2014, p. 57)

INTERLETRAS, ISSN $N^{\circ}$ 1807-1597. V. 9, Edição número 34. Outubro, 2021/ Março de 2022- p

Dossiê: Educação, infância, diversidade e ensino de língua em contexto complexo. 


\section{UMA METODOLOGIA INTERDISCIPLINAR}

Zabala (1998, p.27), afirma que por trás de qualquer proposta metodológica se esconde uma concepção do valor que se atribui ao ensino com certas ideias mais ou menos formalizadas e explícitas em relação ao processo de ensino-aprendizagem.

Com base no pensamento de Zabala (1998), que se apresentou essa proposta de metodologia mista ou interdisciplinar de acordo com os pensamentos de Ginzburg (1990), Vigotski (2001), Montessori (1965), Hoffmann (2005), Kishimoto (2008), Freire (2002), Freinet (1975) e Lozanov (1984) partiu-se de uma apresentação sobre novas metodologias e ferramentas didáticas, direcionada aos futuros professores e alunos de pedagogia com o objetivo de mostrar que pode-se identificar possíveis falhas no processo, resistência docente frente ao novo e uma possível ressignificação da ação docente, com a aplicação de dinâmicas de grupo ao corpo discente, docente e gestor de escolas do ensino básico. Assim, o presente artigo possui uma proposta e uma perspectiva puramente qualitativas, e busca sua prática e sua realização por meio da observação participativa, colaborativa e dinâmica entre professores e alunos.

As aulas foram ministradas de maneira expositiva com o uso da metodologia Quantum Learning baseadas em Georgi Lozanov (1984), que utiliza elementos da Programação Neurolinguística - PNL. Tal metodologia está sendo trabalhada em países da América Latina e Caribe como México e República Dominicana por exemplo.

Como ferramentas metodológicas foram utilizados instrumentos de áudio e vídeo, como projetores, aparelhos de som para o trabalho expositivo com músicas, além de papel colorido, canetas de cores, cartolinas, fitas adesivas para a confecção do material de trabalho entre os próprios alunos, com a ideia de mostrar a capacidade do desenvolvimento de aulas com material de baixo custo.

Como estratégia, a exposição das aulas ministradas foi dividida em duas partes: teórica à respeito da Metodologia Quantum Learning (5 princípios e 8 chaves de excelência), baseadas em Georgi Lozanov (1984), trabalhados na programação Neurolinguística com os envolvimento dos três canais de aprendizagem no conto Por cuatro esquinitas de nada, de Jérôme Ruillier (2014), utilizando o Paradigma Indiciário de Ginzburg (1990) com métodos e técnicas de ensino de Montessori (1965), Vigotski (2001), Freinet (1975) e Freire (2002), bem como com os tipos de avaliação e a avaliação mediadora pregada por Jussara Hoffmann (2005). Na segunda parte, mais prática, ocorreram as discussões e interpretações textuais das frases da obra $\mathrm{O}$ pequeno Príncipe distribuídas em cápsulas associando teoria e prática, na busca por um estreitamento nas relações entre os próprios futuros docentes e a ampliação de horizontes com ideias de aulas mais didáticas, contribuindo mutuamente para uma comunicação mais empática frente a diversidade em contato e uma aprendizagem mais significativa, feliz e emancipadora.

Martins (2016) busca explicar o fenômeno de contato entre culturas na diversidade como um processo constante de autoaceitação do indivíduo, conhecimento sobre o outro em uma relação de alteridade, interação entre ambos, empatia, chegando a uma transformação cultural, onde cada indivíduo sairá com uma visão distinta a inicial sobre a forma de ver a si mesmo e aos demais. Nesse caso específico, com toda a observação

INTERLETRAS, ISSN $N^{o}$ 1807-1597. V. 9, Edição número 34. Outubro, 2021/ Março de 2022- p

Dossiê: Educação, infância, diversidade e ensino de língua em contexto complexo. 
do processo de inclusão dos diferentes no ensino básico e superior e a situação de evasão ou permanência nos estudos, discutidas no momento da exposição ao ser observado que muitas vezes é ocasionada por falta de estímulos. Para tanto, o autor segue com uma conexão de conceitos desde uma visão complementar e interdisciplinar entre pensamentos de autores que trabalham a temática da antropologia e educação e dá o nome de Sobreculturalidade a esse processo.

Segundo Coppete, Fleuri e Stoltz (2014),

Numa perspectiva intercultural, a escola, como contexto institucional, possui um significado de extrema importância. É nela e por meio dela que crianças, jovens e adultos podem interagir de maneira criativa e, segundo Fleuri (1998), compartilhar processos formativos. Muitas e significativas contribuições decorrem da articulação entre propostas e experiências de educação, especialmente no âmbito da educação popular, mas, também, no âmbito da educação básica, assim como nos processos de formação de professores e professoras. (COPPETE; FLEURI; STOLTZ, 2014, p.79)

Por meio de dinâmicas em grupo, estimulando a criatividade, correlacionando com os aspectos teóricos que as orientavam, foi possível refletir sobre as práticas pedagógicas desenvolvidas por alguns alunos da pedagogia no âmbito escolar como possibilidade de ressignificar metodologias de ensino viciadas ou conteudistas, aperfeiçoando-as. Assim, foi gerado um espaço de diálogo e reflexão sobre as práticas pedagógicas humanizadas e inclusivas, pois acredita-se que "[...] na formação permanente dos professores, 0 momento fundamental é o da reflexão crítica sobre a prática. É pensando criticamente a prática de ou de ontem que se pode melhorar a próxima prática.” (FREIRE, 2002, p. 18).

\section{A METODOLOGIA QUANTUM LEARNING}

Quantum Learning é um conjunto de distintas metodologias, baseada principalmente no conceito de Aprendizagem Acelerada de Lozanov (1983), Inteligências Múltiplas: a teoria na prática de Gardner (1995) e na Programação Neurolinguística de Grinder e Bandler (1986). Tal metodologia busca o desenvolvimento de habilidades nos professores para que estes inspirem e potencializem as habilidades dos seus estudantes visando a uma aprendizagem viva, aplicável e prática.

A aplicação da metodologia Quantum Learning está comparada a uma orquestra sinfônica, onde o professor - maestro interpreta uma partitura, desenho, currículo, conteúdo, respeitando o contexto que possui um fundamento teórico, uma atmosfera, um desenho a ser seguido e o entorno, no caso o ambiente. Assim, parte da aplicação de 5 princípios e 8 chaves de excelência:

Princípios: Tudo Fala; tudo tem um propósito; Prova antes de rotular; comemora cada esforço e se vale a pena aprender vale a pena celebrar. (QUANTUM LEARNING NETWORK MÉXICO, 2013, p. 1.12, tradução nossa)

Chaves de excelência: Integridade; erros levam ao êxito; falar com amabilidade; aproveitar ao máximo cada momento; compromisso; responsabilidade nas ações; flexibilidade e balanço das situações. (QUANTUM LEARNING NETWORK MÉXICO, 2013, p. 2.14, tradução nossa)

INTERLETRAS, ISSN N $N^{o}$ 1807-1597. V. 9, Edição número 34. Outubro, 2021/ Março de 2022- p

Dossiê: Educação, infância, diversidade e ensino de língua em contexto complexo. 
Por tanto, os trabalhos com dinâmicas não podem ser vistos simplesmente como um passatempo, tem que estar com uma base teórica vinculada a um propósito e objetivo a ser alcançado na aprendizagem e que seja uma lição que fique na memória, intenção de nossas atividades didáticas, lúdicas e análogas que resultaram na publicação dos livros.

\section{UMA DIDÁTICA LÚDICA E ANÁLOGA}

Segundo Libâneo (2006, pg. 26) a didática é uma teoria geral sobre o ensino e trata do processo de ensino de uma maneira ampla, atuando na seleção de conteúdos e métodos tendo em vista objetivos pedagógicos concretos e abrangentes, nos remetendo a máxima de Comenius, XVII - "ensinar tudo a todos".

Comenius considerado o pai da didática, elevando a didática como ciência e objeto de estudo propõe no Século XVII uma Didática Magna em sua obra de mesmo nome e nos explica:

[...] um método universal de ensinar tudo a todos. E de ensinar com tal certeza, que seja impossível não conseguir bons resultados. E de ensinar rapidamente, ou seja, sem nenhum enfado e sem nenhum aborrecimento para os alunos e para os professores, mas antes com sumo prazer para uns e para outros. E de ensinar solidamente, não superficialmente e apenas com palavras, mas encaminhando os alunos para uma verdadeira instrução, para os bons costumes e para a piedade sincera. Enfim, demonstraremos todas estas coisas a priori, isto é, derivando-as da própria natureza imutável das coisas, como de uma fonte viva que produz eternos arroios que vão, de novo, reunir-se num único rio; assim estabelecemos um método universal de fundar escolas universais [...] isto é, a arte das artes está em formar o homem, o qual é o mais versátil e o mais complexo de todos os animais. Ensinar a arte das artes é, portanto, um trabalho sério e exige perspicácia de juízo, e não apenas de um só homem, mas de muitos, pois um só homem não pode estar tão atento que lhe não passem desapercebidas muitíssimas coisas. (COMENIUS, 2001, p. 3-4)

E assim nos remete a metodologia mista proposta nesse artigo, associando ao Paradigma indiciário de Ginzburg, bem como a metodologia Quantum Learning.

A analogia apresentada na metodologia Quantum Learning, gera uma reflexão. Imaginemos desde uma perspectiva análoga, uma sinfonia orquestrada por um grande maestro e carregada de técnicas complexas entre vários instrumentos e profissionais distintos dentro de suas múltiplas especificidades. A sinfonia seria uma analogia a sala de aula, onde nos músicos estariam encarnados os alunos, orquestrados pelo grande maestro que seria o professor.

Nessa esteira de raciocínio, os instrumentos seriam as ferramentas metodológicas específicas para cada conhecimento e sua capacidade de desenvolvimento. As regras técnicas funcionariam como uma metodologia pronta a ser seguida, as partituras como um currículo acabado e engessado, incapaz de ter alterado o resultado esperado, vindo de cima e deixado por um músico, representado neste ato pelos órgãos da educação.

Surge uma grande indagação: onde está o que podemos chamar de didática?

INTERLETRAS, ISSN No 1807-1597. V. 9, Edição número 34. Outubro, 2021/ Março de 2022- p

Dossiê: Educação, infância, diversidade e ensino de língua em contexto complexo. 
Os músicos podem ter os melhores instrumentos, das melhores marcas, sentados ou apoiados nas cadeiras mais confortáveis, estarem detrás das melhores partituras, das músicas clássicas mais belas. Do mesmo modo se o maestro possuir a melhor das batutas, estar no mais belo púlpito ou palco vestir seu mais belo traje e mesmo assim não garantir que o espírito do momento, a emoção da situação e a ideia de êxito no resultado sejam logrados por todos da mesma maneira.

Nesse momento nos damos conta do significado e de onde se encontra a didática. Ela está na sintonia do maestro com cada músico - aluno, no olhar, no gesto, na atenção individualizada, na observação da relação de cada músico-aluno com seu instrumento, com sua experiência de vida na interação deste com o meio, com os demais músicos alunos - comunidade, fazendo com que o objetivo do momento seja alcançado, que o desenvolvimento da música chegue suave aos ouvidos de todos os envolvidos como um conhecimento fincado tocando as mentes dos músicos e público em geral.

Quando o músico - aluno chega a esse nível de percepção da didática a ele oferecida pelo maestro-professor, encontra seu potencial de produção, na resiliência, criação, recriação, adaptação e transformação, passando a perceber que o currículo antes engessado pode sim ser transformado de acordo como esse foi tocado pela didática - metodologia de ensino do maestro - professor.

Esse é o resultado observado no material produzido pelos alunos, os livros que foram publicados revelam esse potencial em uma espécie de currículo pós feito, como pregado por Faria (2020), com sua experiência prática na Universidade Federal do Amazonas UFAM apresentado no seu artigo Aprendizagem pela pesquisa e Currículo Pós-Feito, onde aborda nesse conceito a não divisão em disciplinas e tão pouco uma organização curricular fechada e nessa esteira defende a construção em conjunto para o conjunto, onde fez uso dos clássicos com respeito para a elaboração de algo novo, aberto e portanto, diferenciado. Como também explica Welter e Martins (2013) sobre o antropólogo Egon Schaden, explicando sobre a antropologia do vovô, a importância sempre de ir às fontes, pois o novo possui raízes muitas vezes remotas.

Nesse mesmo viés, Saviani (1984) nos mostra uma ideia de saber elaborado e saber rudimentar em conjunto, não isolados, não acabados, não estáticos, dinâmicos, transmitidos da cultura acumulada, contribuindo para a produção de novos conhecimentos de maneira dialética.

Snyders (1974) nos diz que os alunos possuem uma experiência prévia que não deve ser ignorada pela escola, desde a antropologia da educação seria o que Aparicio Gervás (2011) denomina de Intraculturalidade, a bagagem cultural, seja pessoal, familiar ou comunitária trazida em um momento de encontro ao diferente, ou seja, repensar o planejamento levando em consideração o contexto sociocultural, político-econômico e histórico dos atores e da diversidade envolvida no momento do fazer pedagógico.

Essa reflexão surge em João Pessoa na Paraíba em um evento no Centro de Educação sobre os projetos de extensão desenvolvidos durante o ano letivo de 2019. Durante as apresentações de bolsistas, monitores e seus respectivos coordenadores de projetos,

INTERLETRAS, ISSN N $N^{\circ}$ 1807-1597. V. 9, Edição número 34. Outubro, 2021/ Março de 2022- p

Dossiê: Educação, infância, diversidade e ensino de língua em contexto complexo. 
fomos surpreendidos pelo grupo Evocare, orquestrado pela Professora Marineuma, que me fez pensar no processo de educação como um todo mais amplo, nas conexões não vistas ou não palpáveis que permeiam a sala de aula, o processo educativo e sua sinergia. Neste momento pude associar a metodologia Quantum Learning de Lozanov (1984), trabalhada em países do Caribe, que como dito anteriormente compara o professor em sala de aula com a atuação de um maestro frente a uma orquestra.

\section{A DIVERSIDADE EM CONTEXTOS COMPLEXOS E AS DINÂMICAS COM CONTOS}

Um dos contos trabalhados nas dinâmicas de grupo, o conto Por cuatro esquinitas de Nada, narra a história de personagens nas formas geométricas de círculos e um quadrado, onde o personagem principal, o quadradinho, se sente excluído da turma de redondinhos por ser o diferente, e passa toda sua narrativa na tentativa de entender essa exclusão e buscar mecanismos para reverter tal situação. Um elemento chave no texto, é a porta redonda, que não permite a passagem do quadradinho. Tal conto nos remete às fábulas de Esopo na antiguidade, onde estão cheias de conceitos implícitos e uma ou várias morais da história. Para Platão e Fiorin (2003) apud Farencena (2011) a fábula mostra explicitamente o que outros textos revelam de forma implícita: "os expedientes discursivos utilizados para ludibriar os outros, para fazer nossos atos parecer o que não são, para camuflar nossas reais intenções". (PLATÃO; FIORIN, 2003, apud FARENCENA, 2011, p. 399).

Alguns conceitos como inclusão, exclusão, aceitação, respeito, interação, especificidades e identidade marcam de forma clara a diversidade encontrada em um ambiente acadêmico e escolar, e nessa diversidade, a multiculturalidade existente na escola, universidade, cidade e Estado.

A Paraíba, Estado que serviu de palco para essa iniciativa é um Estado indígena, um dos poucos do Brasil que possui comunidades nas mesmas terras indígenas da época da colonização, com municípios marcados por essa presença, considerados e aceitos como indígenas, entre eles Baía da Traição, Rio Tinto e Marcação. Além do município do Conde, onde está localizado o Quilombo do Ipiranga, ou seja, a Paraíba é caracterizada como um estado multiétnico.

Tal afirmação me remete a uma das turmas que ao mencionar sobre a presença indígena no estado gerou um espanto por parte de muitos alunos que afirmaram que não havia mais indígenas no Estado. Essa situação é um reflexo dos livros didáticos na educação básica, que conjugaram sempre os verbos relacionados aos povos indígenas no passado, tecendo um papel de esquecimento, além do despreparo da formação docente frente às culturas que formam a identidade do povo brasileiro.

O trabalho didático com contos e dinâmicas de grupo permite, com que se veja de forma clara a diversidade em contato e as relações estabelecidas nesse contato com os diferentes, capaz de proporcionar debates e discussões em uma espécie de avaliação diagnóstica, uma das etapas da avaliação mediadora de Hoffmann (2005), para em seguida saber as INTERLETRAS, ISSN No 1807-1597. V. 9, Edição número 34. Outubro, 2021/ Março de 2022- p

Dossiê: Educação, infância, diversidade e ensino de língua em contexto complexo. 
medidas a serem tomadas como mediação e equiparação da situação por meio da ludicidade.

\section{UM CADERNO PARA AS IDEIAS DE UM JOVEM QUE QUER MUDAR O MUNDO}

Um caderno para as ideias de um jovem que quer mudar o mundo foi a frase que deu início a segunda dinâmica de grupo, que partiu da distribuição de frases e interpretações do livro $\mathrm{O}$ pequeno Príncipe em pequenas cápsulas em que um dos alunos seria contemplado com o prêmio, o caderno, esse aluno seria o responsável por iniciar a escrita e a cada aula o caderno seria passado para um colega. Da dinâmica resultaram os dois livros mencionados anteriormente, que revelaram sonhos, inquietações, anseios e reflexões. Materializaram-se personagens expressando toda uma carga de experiências e sentimentos além das batalhas travadas no cotidiano da formação do profissional da educação.

O primeiro livro, foi escrito por 14 estudantes, da turma de Seminário Temático do Curso de Pedagogia 2019.2, do turno da noite da Universidade Federal da Paraíba - UFPB, com a colaboração de duas crianças, filhos de uma aluna e que sempre estavam presentes nas aulas da sua mãe, participando ativamente das discussões, dinâmicas e atividades propostas, mostraram em suas participações a importância do lúdico, fazendo com que as aulas naquele momento se tornassem canteiros de ideias, pois ficava evidente o interesse despertado nessas crianças em suas participações.

No livro surge o personagem de um jovem chamado Victor, um nome forte que corresponde a uma interjeição usada antigamente para vitoriar, que significa aclamar aquele que acaba de receber o título de doutor, e que por isso terá seu nome gravado nas paredes da Universidade de Salamanca ladeado do anagrama com as letras V I C T O R na cor vermelha, remetendo a cor de sangue, simbolizando luta árdua na conquista do título.

Na história, Victor faz uma analogia com a Rosa de Jericó, uma planta originária da Arábia Saudita, no deserto do Saara e pensa que como ela, que é capaz de viver em grandes períodos de seca, sem nada de água, durante muito tempo, até que seja encontrada, ele também, frente a toda adversidade, pode conseguir transformar-se e revela aos poucos que acredita na sua positividade. (MARTINS; MARTINS; ISAÍAS, 2020, p.9)

O personagem Victor com a cabeça cheia de dúvidas com respeito ao que poderia contribuir para mudar o mundo, se encontrava desmotivado, cabisbaixo, e acaba sendo tomado por um misto de sentimentos. A tristeza, a falta de utopia e a indignação foram alguns que acabaram lhe servindo de impulso na luta pelas mudanças que queria provocar e acaba por escolher a profissão de educador (MARTINS; MARTINS; ISAÍAS, 2020, p.10)

INTERLETRAS, ISSN N $N^{\circ}$ 1807-1597. V. 9, Edição número 34. Outubro, 2021/ Março de 2022- p

Dossiê: Educação, infância, diversidade e ensino de língua em contexto complexo. 
A escolha da profissão ocorre depois de toda uma luta interna na tentativa de encontrar a fórmula capaz de mudar o mundo, e acaba percebendo que sozinho seria impossível, precisaria plantar sementes, ideias capazes de mudar o mundo.

O segundo livro que leva o mesmo nome, foi escrito por 29 estudantes do "Curso de Pedagogia", da turma de Avaliação da aprendizagem 2019.2, do turno da manhã da Universidade Federal da Paraíba - UFPB. A história está baseada no personagem representado por um jovem casado, pai, com a cabeça cheia de dúvidas com respeito ao que poderia contribuir para mudar o mundo. Tinha a convicção de que podia fazê-lo, mas não sozinho. Esse jovem vive no Brasil, um país de dimensões continentais, muito diverso social, econômica e culturalmente e sua rotina reflete toda essa diversidade. Pouco a pouco, ao mesmo tempo que nele se desvelam os maus hábitos da pós-modernidade, também se apresentam vivências de oportunidades que a grande maioria da população não tem, como ir à praia ver tranquilamente o pôr do sol, com tempo para inspirar-se, buscar equilíbrio para o muito que se tem para viver, ensinar e aprender. (MARTINS; MARTINS; BARCELLOS, 2020, p. 2)

Assim como o Pequeno Príncipe, publicado há mais de 75 anos, este livro, na sua simplicidade, traz críticas sociais dirigidas ao modo de vida moderno, evidenciando a forma estranha como os adultos veem as coisas, ressaltando a importância de se manter sempre viva a criança que um dia fomos e renovando a cada dia nossa capacidade não só de sonhar, como de realizar. (MARTINS; MARTINS; BARCELLOS, 2020, p. 2)

Enfim, um conto escrito a 29 mãos nos apresenta um percurso de formação centrado num fazer pedagógico reflexivo, oportunizando conhecer mais um ao outro e suas histórias de vida, e consequentemente, baseando-se no conhecimento científico na relação teoriaprática. (MARTINS; MARTINS; BARCELLOS, 2020, p. 61)

\begin{abstract}
Assumir-se como ser social e histórico, como ser pensante, comunicante, transformador, criador, realizador de sonhos, capaz de ter raiva porque é capaz de amar. Assumir-se como sujeito porque é capaz de reconhecer-se como objeto. A assunção de nós mesmos não significa a exclusão dos outros. É a "outredade" do "não eu", ou do tu, que me faz assumir a radicalidade de meu eu. (FREIRE,1996, p23).
\end{abstract}

De acordo com os comentários de alguns alunos, seus escritos revelavam suas próprias inquietações, anseios e desejos de mudança. O livro serviu para deixar a lição de que pequenos gestos e atitudes podem mudar o mundo e que o professor é capaz de contribuir grandiosamente nessa mudança individual e coletiva.

\title{
CONSIDERAÇÕES FINAIS
}

Observa-se que o lúdico presente em qualquer ambiente educacional proporciona uma aprendizagem mais efetiva e humanizadora, facilita o entendimento em uma comunicação e a torna mais empática. Independente das idades envolvidas no processo de ensinoaprendizagem, os participantes se envolvem no processo resgatando muitas vezes a

INTERLETRAS, ISSN $N^{\circ}$ 1807-1597. V. 9, Edição número 34. Outubro, 2021/ Março de 2022- p

Dossiê: Educação, infância, diversidade e ensino de língua em contexto complexo. 
essência humana de interesse e curiosidade que muitas vezes é ofuscada no processo de amadurecimento do indivíduo.

Todo esse processo pôde ser observado com base nas teorias de estudiosos renomados da educação, mencionados neste artigo. E assim, buscou-se, portanto, mostrar uma ressignificação do fazer docente, de um olhar atento ao resgate da essência humana, principalmente nesse contexto de pandemia, onde a informação está mais acelerada e vistas em telas remotas, sem um calor humano, antes bastante presente nas ações pedagógicas.

Esta discussão partiu do princípio de que o processo educacional tem que ser prazeroso, e dessa ideia conclui-se que o lúdico e a comunicação empática, podem ser ferramentas para um processo eficaz de educação, e a utilização de contos como elementos facilitadores é essencial nesse processo.

Por meio das atividades desenvolvidas foi possível observar que muitas vezes as faltas de estímulos estão associadas a falta de informação ou a falta de oportunidades em momentos de capacitação profissional. A exposição serviu como uma espécie de recarga de baterias e ao mesmo tempo como "choque de realidades", mostrando que se podem realizar atividades lúdicas diversas com materiais que estão ao alcance de todos, com a otimização do tempo de cada profissional e com um resgate da sensibilidade no olhar docente, que se torna escasso com a dureza da luta travada diariamente. "Por trás de qualquer prática educativa sempre há uma resposta a 'por que ensinamos' e 'como se aprende'." (ZABALA, 1998, p.33).

Os resultados, ou seja, os livros publicados tais sejam: "Um caderno para as ideias de um jovem que quer mudar o mundo" e "Um caderno para as ideias de um jovem que quer mudar o mundo: agarrando sonhos" foram apresentados aos autores, somente após publicação, todos pensavam que se tratava de simples processos avaliativos diferenciados, mas não sabiam que seriam publicados, e assim como Antoine de SaintExupéry, não tinham a mínima noção do alcance e repercussão deles. A ideia da submissão surgiu depois, porque foi percebido que essa seria a oportunidade de eternizar na memória de cada aluno, toda a discussão gerada durante a realização das dinâmicas. Além disso, para muitos seria a satisfação de uma primeira publicação, que com lágrimas nos olhos após revelação, soube-se que para muitos se tratava não somente de uma primeira publicação, seria também o incentivo e desejo de ser a primeira de muitas que virão.

Os livros produzidos trazem em sua essência uma iniciativa sensível de um professor implicado na busca de transformar mentes e mundos. Para tanto, os educandos foram instigados a construírem juntos e artesanalmente contos giratórios, por meio de uma metodologia criativa e participativa. Nesse contexto coletivo surgem desenhos, caligrafias, personalidades e olhares diversos de uma mesma realidade que, pelas mãos de cada autor(a), ganhou corpo e alma e a materialização de personagens. Quando o conto começou a ser escrito nada se sabia do seu desfecho. Por isso, tal realidade remete à trama da vida, posto que pouco se conhece sobre os percursos a serem percorridos, mas seguese disposto a aprender, conhecer, mudar, planejar e sonhar. São essas ferramentas INTERLETRAS, ISSN N $N^{\circ}$ 1807-1597. V. 9, Edição número 34. Outubro, 2021/ Março de 2022- p

Dossiê: Educação, infância, diversidade e ensino de língua em contexto complexo. 
simbólicas que também fazem e farão parte da trajetória de cada futuro(a) pedagogo(a) em prol de uma educação humanizada, empática e corajosa. É a lição que fica.

As obras, portanto, são resultados de uma pedagogia do afeto, da resiliência, da perseverança e da sabedoria, do "esperançar" como bem expressa Freire (2001) e que ficarão na memória de todos(as) que fizeram parte das dinâmicas e do projeto de escrita. Trata-se de uma metodologia que também possibilitará a replicação em sala de aula, convidando os(as) educandos(as) a pensarem e repensarem sobre cidadania, inclusão, diversidade e, sobretudo, o importante exercício de sonhar e "esperançar" para si, para o outro e para o mundo.

\section{REFERÊNCIAS}

APARICIO GERVÁS, Jesús María. Interculturalidad, Educación y Plurilingüismo en América Latina. Madrid: Pirámide, 2011.

AUGÉ, Marc. O antropólogo e o mundo global. Petrópolis: Vozes, 2014.

BANDLER, Richard; GRINDER, John. Ressignificando: programação neurolinguística e a transformação do significado. São Paulo: Summus, 1986.

COMENIUS, Iohannis Amos. Didactica Magna. Introdução, Tradução e Notas de Joaquim Ferreira Gomes. Lisboa: Fundação Calouste Gulbenkian, 2001.

COPPETE, Maria Conceição; FLEURI, Reinaldo Matias.; STOLTZ, Tania. Educação Intercultural e Diversidade: perspectivas possíveis. In CERCCHETI, Elcio; POZZER, Adecir (Orgs.). Educação e Interculturalidade: conhecimentos, saberes e práticas descoloniais. Blumenau: edifurb, 2014.

ESOPO. Fábulas completas. Tradução: Maria Celeste Consolin Dezotti. São Paulo: Cosac Naify, 2013.

FARENCENA, Gessélda Somavilla. Fábulas de Esopo e Millôr Fernandes: uma análise contextual. Linguagens \& Cidadania, Santa Maria, v.13, n. 1, jan./dez., 2011.

FARIA, Ivani Ferreira de. Aprendizagem pela pesquisa e currículo pós-feito: uma proposta intercultural para descolonização do saber e autonomia dos povos indígenas. In FARIA, Ivani Ferreira de. et al. (Org.). Descolonizando a academia: cruzando os rios da interculturalidade percorrendo as trilhas do saber para autonomia. Curitiba: CRV, 2020.

FREIRE, Paulo. Pedagogia da autonomia: saberes necessários à prática educativa. São Paulo: Paz e Terra, 2002.

FREIRE, Paulo. Pedagogia dos sonhos possíveis. São Paulo: UNESP, 2001.

INTERLETRAS, ISSN N $N^{\circ}$ 1807-1597. V. 9, Edição número 34. Outubro, 2021/ Março de 2022- p

Dossiê: Educação, infância, diversidade e ensino de língua em contexto complexo. 
FREIRE, Paulo; GUIMARÃES, Sérgio. Partir da infância diálogos sobre educação. São Paulo: Paz e Terra, 2014.

FREIRE, Paulo. Educação como prática da liberdade. 17.ed. Rio de Janeiro: Paz e Terra, 1979.

FREINET, Cèlestin. A educação pelo trabalho. Lisboa: Presença, 1975.

GARDNER, Howard. Inteligências múltiplas: a teoria na prática. Tradução de Maria Adriana Veríssimo Veronese. Porto Alegre: Artes Médicas, 1995.

GINZBURG, Carlo. Mitos, emblemas e sinais. São Paulo: Cia das Letras, 1990.

HOFFMANN, Jussara. Avaliar para promover: as setas do caminho. $7^{a}$ ed. Porto Alegre: Mediação, 2005.

KISHIMOTO, Tizuco Morchida. Jogo, brinquedo, brincadeira e a educação. São Paulo: Cortez, 1996.

KISHIMOTO, Tizuco. Morchida. O brincar e suas teorias. São Paulo: Cengage learning, 2008.

LIBÂNEO, José Carlos. Didática. São Paulo: Cortez, 2006.

LOZANOV, Georgi. Suggestologie et éléments de suggestopédie. Montréal: Science et cultures, 1984.

MARTINS, Daniel Valério. A intraculturalidade nas comunidades indígenas da Região Metropolitana de Fortaleza - CE - Brasil: Caminho para o desenvolvimento e sobreculturalidade. Salamanca: Vitor, 2016.

MARTINS, Daniel Valério; MARTINS, Racquel Valério; BARCELLOS, Antônio Augusto Bonatto. Um caderno para as ideias de um jovem que quer mudar o mundo. João Pessoa: Amazon, 2020. Disponível em: <https://www.amazon.es/caderno-ideiasjovem-mudar-mundo/dp/B08BDZ2HH8>. Acesso em: 03 fev. 2021.

MARTINS, Daniel Valério; MARTINS, Racquel Valério; ISAÍAS, Hector Rocha. Um caderno para as ideias de um jovem que quer mudar o mundo: agarrando sonhos. João Pessoa: UFPB, 2020. Disponível em: <http://www.editora.ufpb.br/sistema/press5/index.php/UFPB/catalog/view/632/843/713 1-1>. Acesso em: 03 fev. 2021.

MONTESSORI, María. Pedagogia científica: a descoberta da criança. São Paulo: Flamboyant, 1965.

INTERLETRAS, ISSN $N^{\circ}$ 1807-1597. V. 9, Edição número 34. Outubro, 2021/ Março de 2022- p

Dossiê: Educação, infância, diversidade e ensino de língua em contexto complexo. 
PLATÃO, Francisco; FIORIN, José Luiz. Para entender o texto. 16 ed. São Paulo: Ática, 2003.

QUANTUM LEARNING NETWORK MÉXICO. Quantum Learning para Maestros: orquestando el éxito de los estudiantes. Oceanside, 2013.

RUILLIER, Jérôme. Por cuatro esquinitas de nada. Barcelona: Juventud, 2014.

SAINT-EXUPÉRY, Antoine de. O pequeno príncipe. Tradução de Dom Marcos Barbosa. Rio de Janeiro: Agir, 2005.

SAVIANI, Demerval. O ensino básico e o processo de democratização da sociedade brasileira. Revista da Associação Nacional de Educação, São Paulo, ano 1, n. 7, p. 913, 1984.

SNYDERS, Georges. Pedagogia Progressista. Coimbra: Almedina, 1974.

VIGOTSKI, Lev. A construção do pensamento e da linguagem. São Paulo: Martins Fontes, 2001.

VIGOTSKI, Lev. Psicologia pedagógica. São Paulo: Martins Fontes, 2004.

WELTER, Tânia; MARTINS, Pedro. Atualidade da Obra de Egon Schaden no centenário de seu nascimento. Plural Revista de Ciências Sociais, São Paulo, v.20, n. 2. p. 173176, 2013.

ZABALA, Antoni. A prática educativa como ensinar. Porto Alegre: Artmed, 1998.

* Professor do Programa de Pós-Graduação em Educação e Territorialidade - PPGET da UFGD. Doutor em Antropologia, Instituto de Ibero-América - USAL, Doutor em Educação Universidade de Burgos-UBU e Pós-Doutor pelo Instituto Histórico e Geográfico de Santa Catarina - IHGSC. Presidente do Grupo Salamanca de Investigación en Antropología Indigenista y Educación Intercultural - GSIAIEI. E-mail: jjfadelino@hotmail.com, ORCID: 0000-0003-0777-9750

** Graduando em Sistemas e Mídias Digitais pela Universidade Federal do Ceará. Membro do Grupo Salamanca de Investigación en Antropología Indigenista y Educación Intercultural - GSIAIEI. E-mail: rocharuan@live.com. ORCID: 0000-0002-0766-2133

INTERLETRAS, ISSN $N^{\circ}$ 1807-1597. V. 9, Edição número 34. Outubro, 2021/ Março de 2022- p

Dossiê: Educação, infância, diversidade e ensino de língua em contexto complexo. 